\title{
Hourly differences in air pollution and risk of respiratory disease in the elderly: a time-stratified case-crossover study
}

Takashi Yorifuji $i^{*}$, Etsuji Suzuki ${ }^{2}$ and Saori Kashima ${ }^{3}$

\begin{abstract}
Background: Epidemiological studies have shown adverse effects of short-term exposure to air pollution on respiratory disease outcomes; however, few studies examined this association on an hourly time scale. We evaluated the associations between hourly changes in air pollution and the risk of respiratory disease in the elderly, using the time of the emergency call as the disease onset for each case.

Methods: We used a time-stratified case-crossover design. Study participants were 6,925 residents of the city of Okayama, Japan, aged 65 or above who were taken to hospital emergency rooms between January 2006 and December 2010 for onset of respiratory disease. We calculated city-representative hourly average concentrations of air pollutants from several monitoring stations. By using conditional logistic regression models, we estimated odds ratios per interquartile-range increase in each pollutant by exposure period prior to emergency call, adjusting for hourly ambient temperature, hourly relative humidity, and weekly numbers of reported influenza cases aged $\geq 60$.

Results: Suspended particulate matter (SPM) exposure 24 to $<72$ hours prior to the onset and ozone exposure 48 to $<96$ hours prior to the onset were associated with the increased risk of respiratory disease. For example, following one interquartile-range increase, odds ratios were 1.05 (95\% confidence interval: 1.01, 1.09) for SPM exposure 24 to $<48$ hours prior to the onset and 1.13 (95\% confidence interval: $1.04,1.23$ ) for ozone exposure 72 to $<96$ hours prior to the onset. Sulfur dioxide $\left(\mathrm{SO}_{2}\right)$ exposure 0 to $<24$ hours prior to onset was associated with the increased risk of pneumonia and influenza: odds ratio was 1.07 per one interquartile-range increase (95\% confidence interval: 1.00, 1.14). Elevated risk for pneumonia and influenza of $\mathrm{SO}_{2}$ was observed at shorter lags (i.e., 8-18 hours) than the elevated risks for respiratory disease of SPM or ozone. Overall, the effect estimates for chronic obstructive pulmonary disease and allied conditions were equivocal.
\end{abstract}

Conclusions: This study provides further evidence that hourly changes in air pollution exposure increase the risks of respiratory disease, and that $\mathrm{SO}_{2}$ may be related with more immediate onset of the disease than other pollutants.

Keywords: Air pollution, Ozone, Particulate matter, Respiratory disease, Short-term effect, Sulfur dioxide

\section{Background}

A large number of epidemiological studies have shown adverse effects of short-term exposure to air pollution on respiratory disease outcomes [1-5], although most epidemiological studies to date have evaluated the association between daily air pollution and daily counts of respiratory outcomes. For example, a recent multi-city

\footnotetext{
* Correspondence: yorichan@md.okayama-u.ac.jp

'Department of Human Ecology, Graduate School of Environmental and Life Science, Okayama University, 3-1-1 Tsushima-naka, Kita-ku, Okayama 700-8530, Japan

Full list of author information is available at the end of the article
}

study across Europe and North America examined the effect of daily exposure levels (e.g., lag 1 day, average of lags 0 and 1 days) on daily mortality or hospitalizations [6]. Several studies therefore attempted to examine the effect of alternative pollutant metrics other than the 24hour average on respiratory outcomes. Darrow et al. evaluated the different temporal metrics of air pollution (e.g., a daily 1-hour maximum, a day-time average, a night-time average) on the following days' respiratory emergency visits and found that the different temporal metrics were also associated with the risk of visits [7]. 
Moreover, Stieb et al. examined the association between 3 -hour averages of emergency visits and 3-hour average pollutant concentrations lagged up to 12 hours before, but found no association [8]. These attempts are, however, rare; thus, the epidemiological evidence on the association at an hourly temporal resolution between exposure to air pollution and the risk of respiratory outcomes is limited.

A recent study suggested that air pollution exposure caused more immediate effects on cardiovascular diseases and more delayed effects on respiratory diseases [9]. Indeed, a small number of epidemiological studies have examined the effect of hourly variations in air pollution on cardiovascular outcomes (such as ischemic heart disease $[10,11]$, ischemic stroke [12-14], or hemorrhagic stroke [15] and demonstrated possible immediate adverse effects (e.g., 1-6 hours later [10]). These transient increases in risk immediately following air pollution exposure are supported by experimental studies [16,17]. Similarly, several experimental studies have demonstrated possible pulmonary function decrements immediately after air pollution exposure and pulmonary inflammation responses 16 to 18 hours after the exposure $[18,19]$. However, epidemiological studies so far cannot provide further evidence on these finer temporal associations (i.e., hourly time-scale) between air pollution and respiratory outcomes.

We therefore evaluated the associations between hourly changes in air pollution and the risk of respiratory disease onset in residents of Okayama, Japan, who had visited emergency rooms between January 2006 and December 2010. The findings may provide additional insights into the physiological mechanisms of air pollution health effects.

\section{Methods}

\section{Study subjects}

The Ambulance Division of the Fire Bureau in the city of Okayama provided electronic data (stripped of patient names) on all ambulance calls during the study period [20]. The call was made by the patients themselves or by others to request an ambulance. From the data, we selected 110,110 residents who had been brought to emergency rooms by ambulance between January 2006 and December 2010 in Okayama, a city located in the western part of Japan with population of 709,584 (151,140 people aged 65 or above) and an area of $790 \mathrm{~km}^{2}$ (in 2010). We restricted study participants to 6,925 patients aged 65 or above who were brought to an emergency room because of respiratory disease. We focused on the elderly because they are considered to be at greater risk of the adverse health effects of outdoor air pollution [2]. Because we could not differentiate each patient on the data, we might have counted the same participants more than once. The type of disease was diagnosed by physicians at the emergency rooms of the hospitals to which the patients were transported. Because we did not have the exact times of the disease onsets, we used the time of the emergency call as the disease onset for each case.

\section{Air pollution, meteorological, and influenza data}

We obtained hourly concentrations of suspended particulate matter (SPM), nitrogen dioxide $\left(\mathrm{NO}_{2}\right)$, sulfur dioxide $\left(\mathrm{SO}_{2}\right)$, ozone, and carbon monoxide $(\mathrm{CO})$, measured at monitoring stations in the city of Okayama during the study period, from the Okayama Prefectural Government. Particulate matter (PM) is measured as SPM in Japan and accounts for PM with an aerodynamic diameter less than $7 \mu \mathrm{m}\left(\mathrm{PM}_{7}\right)$. During the study period, 11 stations were used for SPM measurements, 11 for $\mathrm{NO}_{2}$, seven for $\mathrm{SO}_{2}$, eight for ozone, and two for $\mathrm{CO}$. The entire area of the city is covered by $30-\mathrm{km}$ buffers from each monitoring station. We then calculated city-representative hourly average concentrations of each air pollutant from hourly concentrations at each monitoring station. When hourly concentrations at several monitoring stations were not available, we used hourly concentrations at other stations where the data was available to calculate the cityrepresentative hourly average concentrations. Despite these imputations, we lacked 502 hourly concentrations for ozone (1.15\% of eligible hours) and 26 for CO (0.06\% of eligible hours) during the study period.

We also obtained hourly temperature and relative humidity during the study period from one weather station in the city of Okayama managed by the Japan Metrological Agency. There were no missing data for temperature and relative humidity.

We obtained weekly numbers of reported influenza cases among monitoring medical institutions in the city from the website of the public health center in the Okayama city [21].

\section{Health outcomes}

The type of disease was diagnosed by medical doctors at the emergency rooms of the hospitals to which the patients were transported, and coded in accordance with the $10^{\text {th }}$ International Classification of Disease (ICD-10). We used the following diseases as main outcomes based on the previous studies [22]: respiratory disease (ICD-10: J00-99), pneumonia and influenza (J10-22), and chronic obstructive pulmonary disease (COPD) and allied conditions (J40-47).

\section{Statistical analyses}

We used a time-stratified, case-crossover design. A casecrossover design can be considered as a case-control version of a cross-over study and can adjust for timeinvariant confounders [23]. The design uses cases only; for each individual case, exposure before the event (case period) is compared with exposure at other control (or 
"referent") periods. Time-stratified referent selection is recommended to ensure unbiased estimates from conditional logistic regression and to avoid bias resulting from time trend [23]; we thus selected control periods from the same times on other days, on the same days of the week in the same months and years (e.g., the same six-hour intervals on other days, on the same days of the week in the same months and years as those on which the case occurred).

We conducted conditional logistic regression analyses to estimate adjusted odds ratios (ORs) and 95\% confidence intervals (CIs) for the association between air pollution exposure and each health outcome. We used exposure data as continuous variables and estimated adjusted ORs for an interquartile range (IQR) increase in each air pollutant during the study periods. In all analyses, we adjusted for hourly ambient temperature using a natural spline with 6 degrees of freedom (df), hourly relative humidity with $3 \mathrm{df}$, and weekly numbers of reported influenza cases aged $\geq 60$ among monitoring medical institutions in the city. We chose the number of $\mathrm{df}$ following a previous air pollution study in Japan [22] and because the relationship between temperature or humidity and morbidity is considered nonlinear. We used meteorological data at the time of the case event.

We first evaluated the effect of exposure to each pollutant, averaged during eight different periods prior to the case event (i.e., emergency calls) ( 0 to $<6$ hours, 6 to $<12$ hours, 12 to $<18$ hours, 18 to $<24$ hours, 0 to $<24$ hours, 24 to $<48$ hours, 48 to $<72$ hours, and 72 to $<96$ hours), on health outcomes (respiratory disease, pneumonia and influenza, and COPD and allied conditions). In addition, we applied quadratic distributed lag models to estimate the cumulative effects of the current and the 3 previous days (i.e., <96 hours before) (lags 03 days) instead of applying single lag models [24]. We further performed a multi-pollutant model to differentiate the role of each pollutant if some of the pollutants were associated with the same outcomes.

To evaluate the effect of shorter exposure in detail, we evaluated the effect of selected air pollutants (which were associated with health outcomes in the singlepollutant models) averaged for 2-hour increments prior to the case event (i.e., 0 to $<2$ hours through 46 to $<48$ hours). We included all periods in the model individually.

In additional analyses, we evaluated whether the effects of these selected pollutants were modified by patient characteristics: age ( $<75$ years vs. $\geq 75$ years), sex, time of onset ( 8 am to 7 pm vs. 8 pm to 7 am), history of hypertension, history of coronary heart disease, history of cerebrovascular disease, history of diabetes mellitus, and history of respiratory disease. The information on comorbidity was obtained from the patients themselves or their relatives by ambulance personnel. The $\mathrm{p}$ values for interaction less than 0.05 were considered significant.

In sensitivity analyses, to reduce exposure measurement error, we excluded two areas located in the northern part of the city of Okayama (the towns of Takebe and Mitsu) so that the study area could be covered by $20-\mathrm{km}$ buffers from each monitoring station. In addition, we repeated the analyses without adjusting for weekly numbers of reported influenza cases. We also excluded influenza cases from the health outcome of pneumonia and influenza and repeated the analysis. Finally, we changed number of dfs for hourly ambient temperature and hourly relative humidity to examine the robustness of the results.

We conducted analyses using the $\mathrm{R}$ statistical package version 2.15.0 [25]. The Institutional Review Board of Graduate School of Medicine, Dentistry and Pharmaceutical Sciences, Okayama University approved this study on 26 June 2012 (No. 556).

\section{Results}

Table 1 presents the characteristics of the participants. More than $20 \%$ of the patients had a history of respiratory disease, and about half of the emergency room visits were for pneumonia and influenza.

During the study period, the IQRs of air pollutants were $20.6 \mu \mathrm{g} / \mathrm{m}^{3}$ for SPM, $11.1 \mathrm{ppb}$ for $\mathrm{NO}_{2}, 2.3 \mathrm{ppb}$ for $\mathrm{SO}_{2}, 25.8 \mathrm{ppb}$ for ozone, and $0.3 \mathrm{ppm}$ for $\mathrm{CO}$ (Table 2). Concentrations for SPM, $\mathrm{SO}_{2}$, and ozone were higher in the daytime, while concentration for $\mathrm{NO}_{2}$ was higher in the nighttime. Hourly SPM was moderately correlated with other pollutants except ozone. By contrast, ozone was weakly correlated with $\mathrm{SO}_{2}$ or inversely associated with $\mathrm{NO}_{2}$ or $\mathrm{CO}$. Averages of temperature and relative humidity were $16.7^{\circ} \mathrm{C}$ and $65.3 \%$, respectively.

When we examined the effect of each pollutant averaged at eight different periods prior to the case event, SPM (24 to $<72$ hours prior to the onset) and ozone (48 to $<96$ hours prior to the onset) exposures were associated with the risk of respiratory disease (Table 3). Following one IQR increase, ORs were 1.05 (95\% CI: 1.01, 1.09) for SPM exposure 24 to $<48$ hours prior to the onset and 1.13 (95\% CI: 1.04, 1.23) for ozone exposure 72 to $<96$ hours prior to the onset. The point estimates from distributed lag models were also elevated for both pollutants. For pneumonia and influenza, the highest and the most precise OR was observed for $\mathrm{SO}_{2}$ exposure 0 to $<24$ hours prior to onset $(\mathrm{OR}=1.07,95 \% \mathrm{CI}$ : $1.00,1.14)$. In contrast, the effect estimates for COPD and allied conditions were equivocal. Even in the two-pollutant model, which adjusted for SPM and ozone at the same exposure periods prior to the onset, the results for respiratory disease did not change (data not shown). Moreover, even if we adjusted for both SPM and ozone exposures 0 to $<24$ hours prior to onset, the OR for pneumonia and 
Table 1 Characteristics of emergency hospital visits of people over 65 years of age with respiratory disease residing in Okayama-city, Japan, 2006-2010 $(n=6,925)$

\begin{tabular}{|c|c|}
\hline & Patients \\
\hline Mean Age (year) (SD) & $82(8.3)$ \\
\hline Sex $(\% \text { women })^{a}$ & $3003(43.4)$ \\
\hline Emergency call (\% daytime, 8 am to 8 pm) ${ }^{a}$ & $4871(70.3)$ \\
\hline \multicolumn{2}{|l|}{ Medical history ${ }^{a}$} \\
\hline Hypertension & $559(8.1)$ \\
\hline Coronary heart disease & $209(3.0)$ \\
\hline Cerebrovascular disease & $1012(14.6)$ \\
\hline Diabetes mellitus & $369(5.3)$ \\
\hline Respiratory disease & $1574(22.7)$ \\
\hline Other diseases & $2292(33.1)$ \\
\hline None & $459(6.6)$ \\
\hline Unknown & $451(6.5)$ \\
\hline \multicolumn{2}{|l|}{ Types of respiratory disease ${ }^{a}$} \\
\hline Pneumonia and influenza & $3227(46.6)$ \\
\hline COPD and allied conditions & $767(11.1)$ \\
\hline Acute upper respiratory infections & $297(4.3)$ \\
\hline Other diseases of upper respiratory tract & $303(4.4)$ \\
\hline Lung diseases due to external agents & $1118(16.1)$ \\
\hline $\begin{array}{l}\text { Other respiratory diseases principally affecting the } \\
\text { interstitium }\end{array}$ & $120(1.7)$ \\
\hline $\begin{array}{l}\text { Suppurative and necrotic conditions of lower } \\
\text { respiratory tract }\end{array}$ & $15(0.2)$ \\
\hline Other diseases of pleura & $264(3.8)$ \\
\hline Other diseases of the respiratory system & $814(11.8)$ \\
\hline
\end{tabular}

${ }^{\mathrm{a}} \mathrm{No.}(\%)$ of participants is shown.

COPD; Chronic obstructive pulmonary disease, SD; Standard deviation.

influenza was still elevated for $\mathrm{SO}_{2}$ exposure 0 to $<24$ hours prior to onset (OR $=1.07,95 \%$ CI: $0.99,1.17$ ).

We examined the effect of exposure within 48 hours of the onset of respiratory disease in more detail (Figure 1): SPM exposure 30-48 hours before onset was associated with elevated risks of respiratory disease, while ozone exposure was not associated with the elevated risk of respiratory disease within 48 hours of the onset as expected from Table 3. By contrast, $\mathrm{SO}_{2}$ exposure was associated with the elevated risk of pneumonia and influenza in smaller number of hours prior to the onset (e.g., 8-18 hours) (Figure 2).

In stratified analyses by patient characteristics (Table 4), effect estimates for the association between ozone exposure and respiratory disease were higher for women and those without a history of diabetes mellitus. In addition, effect estimates for the association of $\mathrm{SO}_{2}$ exposure with pneumonia and influenza were higher for those with a history of hypertension and those without histories of cerebrovascular and respiratory diseases. However, a statistically significant interaction was observed only for the stratification by a disease history of respiratory disease for the association of $\mathrm{SO}_{2}$ with pneumonia and influenza.

In sensitivity analyses, exclusion of the towns of Takebe and Mitsu from the analyses provided similar results: e.g., ORs for respiratory disease were 1.05 (95\% CI: 1.01, 1.09) for SPM exposure 24 to $<48$ hours prior to the case events and 1.13 (95\% CI: 1.04, 1.23) for ozone exposure 72 to $<96$ hours prior to the case events and OR for pneumonia and influenza was 1.06 (95\% CI: 1.00, 1.13) for $\mathrm{SO}_{2}$ exposure 0 to $<24$ hours prior to the case events. Not adjusting for weekly numbers of reported influenza cases also provided similar results (data not shown), which implies that influenza epidemics did not confound the association between short-term exposure to air pollution and respiratory health effects. Moreover, when we excluded influenza cases $(\mathrm{n}=111)$ from the analysis, OR for pneumonia and influenza was 1.06 (95\% CI: $1.00,1.14)$ for $\mathrm{SO}_{2}$ exposure 0 to $<24$ hours prior to the case events. Finally, when we adopted different numbers of dfs (hourly ambient temperature with $8 \mathrm{dfs}$ and hourly relative humidity with 5 dfs), the results did not change (data not shown).

\section{Discussion}

In the present study, we evaluated the associations between hourly changes in air pollution and the risk of respiratory disease onset in Okayama, Japan, using the time of the emergency call as the disease onset for each case. We found that SPM $\left(\mathrm{PM}_{7}\right)$ exposure 24 to $<72$ hours prior to the onset and ozone exposure 48 to $<96$ hours prior to the onset were associated with

Table 2 Characteristics and Spearman correlation coefficients for hourly air pollutants and meteorological variables

\begin{tabular}{|c|c|c|c|c|c|c|c|c|c|c|c|}
\hline & \multicolumn{3}{|c|}{ Mean (SD) } & \multirow[t]{2}{*}{ IQR } & \multirow[t]{2}{*}{ SPM } & \multirow[t]{2}{*}{$\mathrm{NO}_{2}$} & \multirow[t]{2}{*}{$\mathrm{SO}_{2}$} & \multirow[t]{2}{*}{ Ozone } & \multirow[t]{2}{*}{$\mathrm{CO}$} & \multirow[t]{2}{*}{ Temperature } & \multirow{2}{*}{$\begin{array}{l}\text { Relative } \\
\text { humidity }\end{array}$} \\
\hline & All day & Daytime (8 am to $7 \mathrm{pm}$ ) & Nighttime (8 pm to $7 \mathrm{am})$ & & & & & & & & \\
\hline $\operatorname{SPM}\left(\mu \mathrm{g} / \mathrm{m}^{3}\right)$ & $26.8(18.3)$ & $27.5(18.4)$ & 26.1 (18.1) & 20.6 & 1 & 0.41 & 0.50 & 0.06 & 0.35 & 0.23 & 0.00 \\
\hline $\mathrm{NO}_{2}(\mathrm{ppb})$ & $17.1(8.1)$ & $15.9(7.9)$ & $18.3(8.2)$ & 11.1 & & 1 & 0.40 & -0.40 & 0.63 & -0.26 & 0.20 \\
\hline $\mathrm{SO}_{2}(\mathrm{ppb})$ & $3.0(2.5)$ & $3.7(3.0)$ & $2.3(1.7)$ & 2.3 & & & 1 & 0.26 & 0.19 & 0.22 & -0.31 \\
\hline Ozone (ppb) & $25.9(17.9)$ & $33.8(18.5)$ & $18.1(13.1)$ & 25.8 & & & & 1 & -0.31 & 0.36 & -0.65 \\
\hline $\mathrm{CO}(\mathrm{ppm})$ & $0.6(0.3)$ & $0.6(0.3)$ & $0.6(0.3)$ & 0.3 & & & & & 1 & -0.17 & 0.17 \\
\hline
\end{tabular}

$\mathrm{CO}$, Carbon monoxide; IQR, Interquartile range; $\mathrm{NO}_{2}$, Nitrogen dioxide; $\mathrm{SD}$, Standard deviation; $\mathrm{SO}_{2}$, Sulfate dioxide; SPM, Suspended particulate matter. 
Table 3 Adjusted OR and $95 \% \mathrm{Cl}$ per interquartile-range increase ${ }^{a}$ in each pollutant by exposure period prior to emergency call

Respiratory disease

\section{SPM}

0 to $<6$ hours

6 to $<12$ hours

12 to $<18$ hours

18 to $<24$ hours

0 to $<24$ hours

24 to $<48$ hours

48 to $<72$ hours

72 to $<96$ hours

Distributed lags ${ }^{b}$

$\mathrm{NO}_{2}$

0 to $<6$ hours

6 to $<12$ hours

12 to $<18$ hours

18 to $<24$ hours

0 to $<24$ hours

24 to $<48$ hours

48 to $<72$ hours

72 to $<96$ hours

Distributed lags ${ }^{b}$

$\mathrm{SO}_{2}$

0 to $<6$ hours

6 to $<12$ hours

12 to $<18$ hours

18 to $<24$ hours

0 to $<24$ hours

24 to $<48$ hours

48 to $<72$ hours

72 to $<96$ hours

Distributed lags ${ }^{b}$

\section{Ozone}

0 to $<6$ hours

6 to $<12$ hours

12 to $<18$ hours

18 to $<24$ hours

0 to $<24$ hours

24 to $<48$ hours

48 to $<72$ hours

72 to $<96$ hours

Distributed lags ${ }^{b}$

CO

0 to $<6$ hours

6 to $<12$ hours
$1.03(0.99,1.06)$

$1.02(0.98,1.05)$

$1.02(0.98,1.05)$

$1.03(0.99,1.07)$

$1.05(1.01,1.09)$

$1.03(1.00,1.07)$

$1.05(1.00,1.12)$

$1.02(0.97,1.08)$

$1.04(0.98,1.09)$

$1.03(0.98,1.08)$

$1.02(0.97,1.07)$

$1.04(0.98,1.11)$

$1.05(0.99,1.11)$

$1.02(0.96,1.08)$

$0.98(0.92,1.04)$

$1.05(0.95,1.15)$

$1.01(0.98,1.05)$

$1.02(0.98,1.06)$

$1.03(1.00,1.07)$

$1.01(0.98,1.04)$

$1.03(0.99,1.08)$

$1.03(0.98,1.07)$

$1.02(0.98,1.07)$

$1.01(0.96,1.05)$

$1.05(0.98,1.11)$

$1.01(0.94,1.09)$

$1.02(0.94,1.09)$

$1.04(0.97,1.12)$

$1.02(0.96,1.09)$

$1.04(0.95,1.15)$

$0.98(0.89,1.06)$

$1.09(1.00,1.19)$

$1.13(1.04,1.23)$

$1.15(1.01,1.32)$

$1.00(0.96,1.05)$

$1.00(0.95,1.04)$
$1.03(0.99,1.06)$

$1.01(0.97,1.05)$
Pneumonia and influenza

COPD and allied conditions

$1.02(0.97,1.07)$

$1.06(0.96,1.17)$

$1.03(0.98,1.09)$

$1.02(0.93,1.12)$

$1.01(0.96,1.06)$

$1.00(0.90,1.11)$

$1.01(0.96,1.07)$

$0.97(0.87,1.07)$

$1.02(0.91,1.14)$

$0.99(0.88,1.10)$

$0.98(0.88,1.09)$

$0.90(0.80,1.02)$

$0.93(0.79,1.10)$

$1.05(0.97,1.14)$

$0.97(0.83,1.13)$

$1.03(0.88,1.20)$

$0.99(0.85,1.15)$

$0.89(0.77,1.04)$

$0.95(0.78,1.15)$

$1.01(0.84,1.22)$

$0.96(0.80,1.14)$

$0.84(0.70,0.99)$

$0.83(0.63,1.10)$

$1.02(0.92,1.13)$

$0.96(0.86,1.07)$

$1.04(0.94,1.15)$

$0.99(0.91,1.08)$

$1.00(0.88,1.14)$

$0.97(0.86,1.10)$

$0.94(0.83,1.06)$

$0.85(0.74,0.96)$

$0.85(0.71,1.03)$

$0.94(0.84,1.05)$

$1.10(0.88,1.39)$

$1.04(0.84,1.29)$

$1.15(0.93,1.43)$

$1.27(1.03,1.55)$

$1.29(0.96,1.74)$

$1.00(0.76,1.32)$

$0.98(0.75,1.28)$

$1.21(0.93,1.58)$

$1.36(0.89,2.09)$

$0.99(0.87,1.12)$

$0.93(0.82,1.06)$ 


\section{Table 3 Adjusted $\mathrm{OR}$ and $95 \% \mathrm{Cl}$ per interquartile-range increase ${ }^{\mathrm{a}}$ in each pollutant by exposure period prior to emergency call (Continued)}

\begin{tabular}{lllr}
\hline 12 to $<18$ hours & $0.99(0.95,1.04)$ & $0.99(0.93,1.05)$ & $0.96(0.84,1.09)$ \\
18 to $<24$ hours & $0.99(0.95,1.04)$ & $0.99(0.93,1.05)$ & $0.89(0.78,1.01)$ \\
0 to $<24$ hours & $0.99(0.94,1.05)$ & $0.99(0.91,1.07)$ & $0.90(0.76,1.07)$ \\
24 to $<48$ hours & $1.03(0.98,1.09)$ & $1.05(0.97,1.13)$ & $0.96(0.82,1.12)$ \\
48 to $<72$ hours & $1.00(0.95,1.05)$ & $0.99(0.92,1.07)$ & $0.97(0.84,1.12)$ \\
72 to $<96$ hours & $0.94(0.90,0.99)$ & $0.94(0.88,1.01)$ & $0.81(0.70,0.94)$ \\
Distributed lags $^{b}$ & $0.96(0.89,1.04)$ & $0.95(0.85,1.07)$ & $0.78(0.61,0.99)$
\end{tabular}

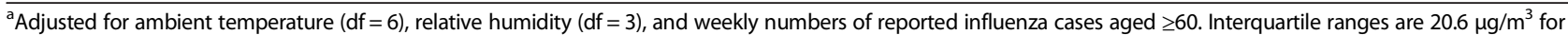
$\mathrm{SPM}, 11.1 \mathrm{ppb}$ for $\mathrm{NO}_{2}, 2.3 \mathrm{ppb}$ for $\mathrm{SO}_{2}, 25.8 \mathrm{ppb}$ for ozone, and $0.3 \mathrm{ppm}$ for $\mathrm{CO}$.

${ }^{\mathrm{b}}$ Quadratic distributed lag (0 to lag 3).

$\mathrm{Cl}$, Confidence interval; $\mathrm{CO}$, Carbon monoxide; $\mathrm{COPD}$; Chronic obstructive pulmonary disease, $\mathrm{NO}_{2}$, Nitrogen dioxide; $\mathrm{OR}$, Odds ratio; $\mathrm{SO}_{2}$, Sulfate dioxide; $\mathrm{SPM}_{4}$ Suspended particulate matter.

the increased risk of respiratory disease, while $\mathrm{SO}_{2}$ exposure 0 to $<24$ hours prior to onset was associated with the increased risk of pneumonia and influenza. Indeed, elevated risk for pneumonia and influenza of $\mathrm{SO}_{2}$ was observed at shorter lags (i.e., 8-18 hours) than the elevated risks for respiratory disease of SPM or ozone.

The observed respiratory effect of SPM, ozone, and $\mathrm{SO}_{2}$ are consistent with previous findings [2,5]. To interpret the finding, one point should be noted that SPM $\left(\mathrm{PM}_{7}\right)$ are particles larger than PM with less than $2.5 \mu \mathrm{m}\left(\mathrm{PM}_{2.5}\right)$ but smaller than PM with less than $10 \mu \mathrm{m}\left(\mathrm{PM}_{10}\right)$; thus, SPM is also included in the range of respirable fraction. A large number of studies have shown that PM (both $\mathrm{PM}_{2.5}$ and $\left.\mathrm{PM}_{10}\right)$ and ozone are associated with an increased risk of respiratory mortality or morbidity $[1,5,26]$. The consistency of the effects of $\mathrm{SO}_{2}$ is less than that of PM or ozone. However, meta-analytic studies or multi-city studies have consistently shown that $\mathrm{SO}_{2}$ also has adverse effects on respiratory outcomes [5,27-29], which are supported by intervention studies in Hong Kong, where an immediate fall in ambient $\mathrm{SO}_{2}$ was observed following restricting sulfur in fuel [30,31].

Different lag structures (i.e., 8-18 hours for $\mathrm{SO}_{2} ; 1-2$ days for SPM; and 2-3 days for ozone) for respiratory outcomes merit consideration. The lags for SPM or ozone are plausible considering the previous studies $[6,8,22,32]$. The shorter lag for $\mathrm{SO}_{2}$ may be supported by an experimental study which demonstrated a mild increase in neutrophils in the fluid obtained by bronchoalveolar lavage 18 hours after concentrated ambient air particles exposure $[18,33]$. Basically, $\mathrm{SO}_{2}$ can be converted to sulfuric acid and contribute to the formation of PM [34]. In the experimental study we mentioned, sulfuric acid was highly correlated with the particles. Although it may be difficult to attribute this immediate increased risk $\mathrm{SO}_{2}$ itself, $\mathrm{PM}$ may become more toxic and have immediate effects when $\mathrm{SO}_{2}$ coexists and gets absorbed onto PM surfaces [5].

Compared to respiratory disease or pneumonia and influenza, the findings for COPD and allied conditions were equivocal, which is inconsistent with the previous studies [2]. This is probably due to small number of cases in the present study. Because we could not include patients who arrived at hospitals by their own means, this may reduce the number of the COPD cases in the present study.

We also observed that several patient characteristics were associated with increased risk of air pollution. The higher effect estimate for women of the association between ozone exposure and respiratory disease is consistent with a multi-city study in Asia [35], but a study in Massachusetts, US, did not find effect modification by sex [36]. Among preexisting diseases, we observed a statistically significant interaction only for respiratory disease: those without a history of respiratory disease had a higher effect estimate for the association of $\mathrm{SO}_{2}$ exposure with pneumonia and influenza. Although the reason is unclear and we have no other evidence, those without respiratory disease may be more sensitive to the exposure or be exposed more heavily, probably because they can stay outdoors longer. However, a previous study with a cohort of COPD patients in Italy suggested those with preexisting disease history (in particular, heart conduction disorders and cerebrovascular disease) were more susceptible to air pollution [37]. Further investigation may be needed.

The strength of the present study is that we could obtain hourly data on both air pollution and emergency visits, which enabled us to examine the effect of hourly changes in air pollution on the risk of respiratory disease. Previous mortality studies were not able to determine whether air pollution could trigger new respiratory disease events or precipitate the deaths of patients with preexisting disease [4,5], and their use of a daily time scale prevented determination of an exact temporal relationship between air pollution exposure and disease onset. In addition, we were able to obtain individual information (e. g., preexisting disease), and thus could evaluate effect modifications of these individual characteristics.

However, several limitations should be noted. First, most of the reported associations were not statistically 


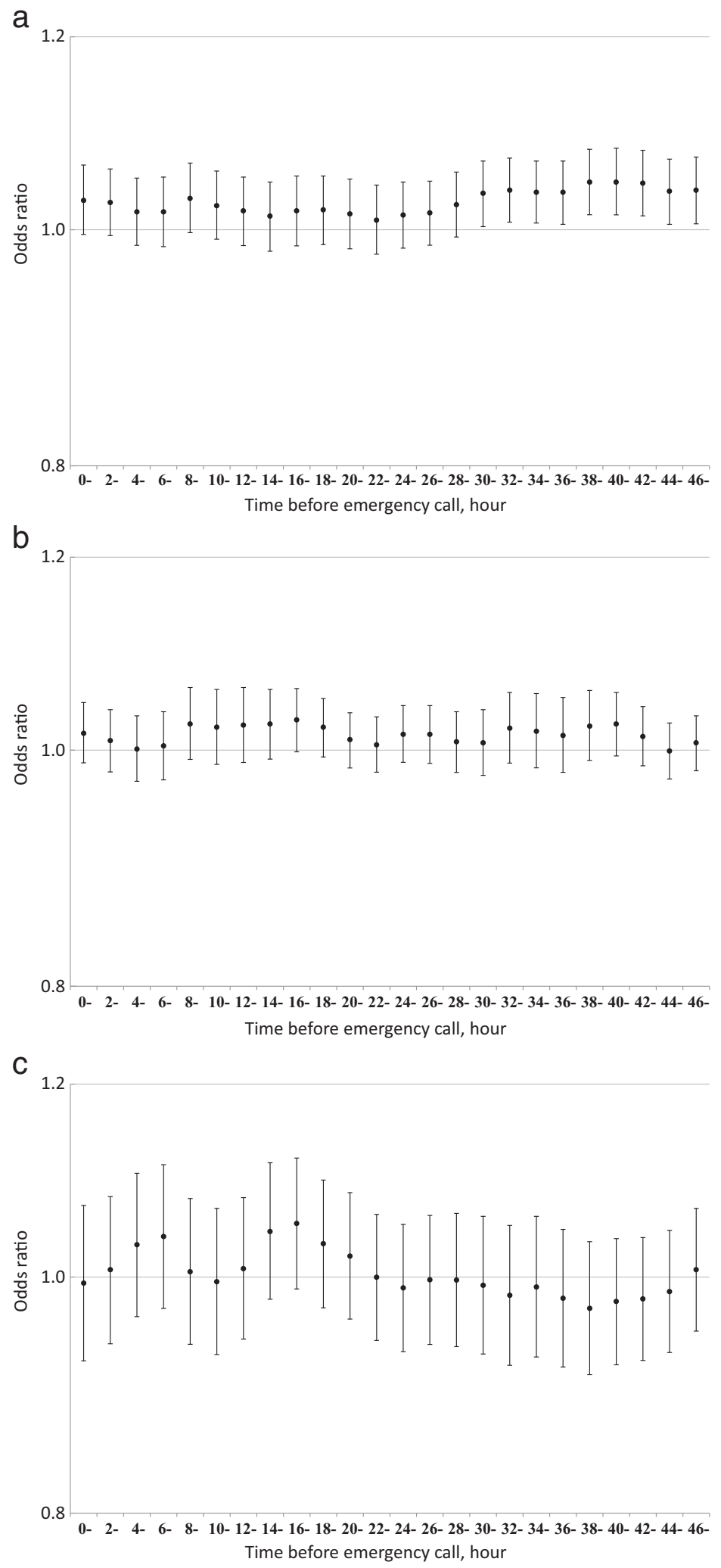

Figure 1 Odds ratios of respiratory disease for an interquartile range increase in (a) suspended particulate matter $\left(20.6 \mu \mathrm{g} / \mathrm{m}^{3}\right),(\mathrm{b})$ sulfur dioxide (2.3 ppb), and (c) ozone (25.8 ppb) in the hours prior to disease onset. Vertical bars indicate $95 \%$ confidence intervals. 


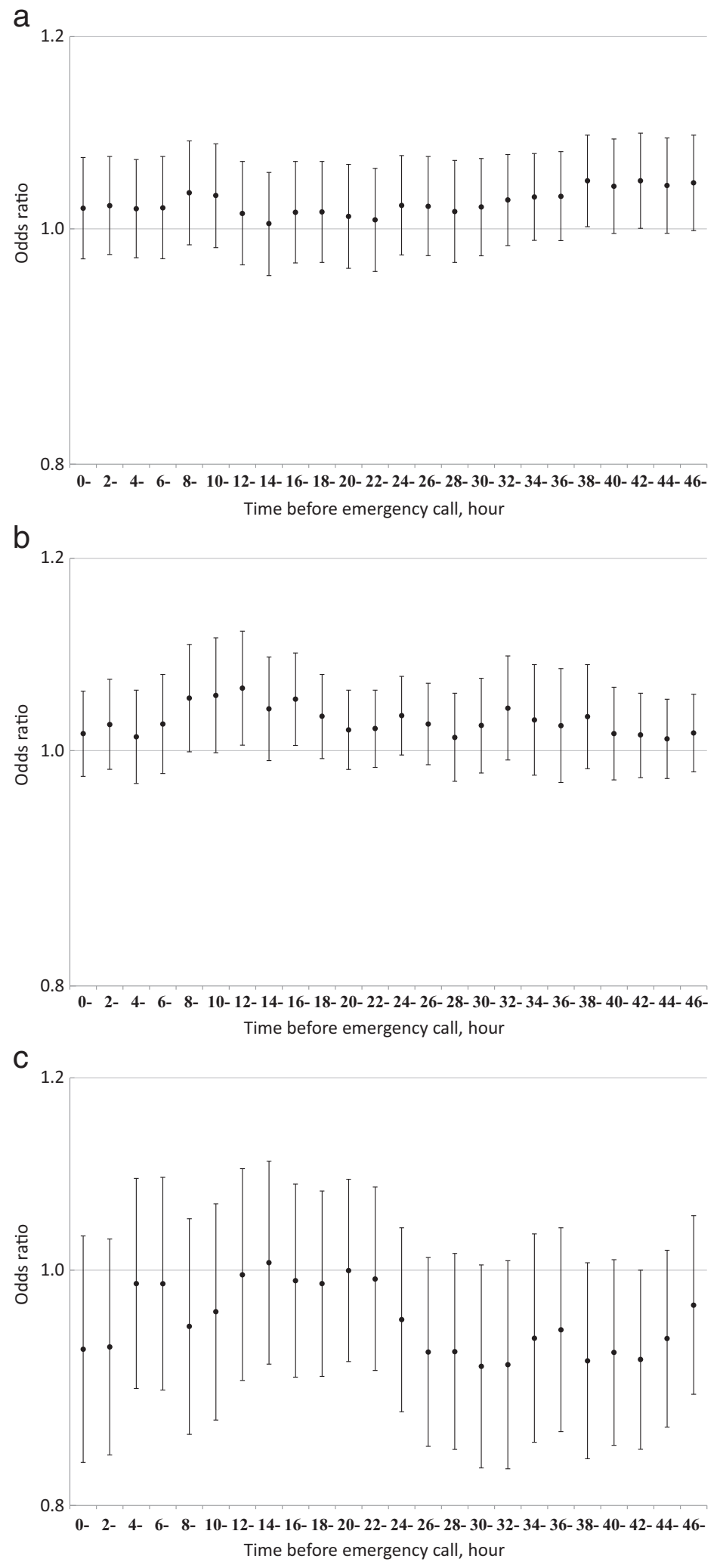

Figure 2 Odds ratios of pneumonia and influenza for an interquartile range increase in (a) suspended particulate matter $\left(20.6 \mu \mathrm{g} / \mathrm{m}^{3}\right)$, (b) sulfur dioxide $(2.3 \mathrm{ppb})$, and (c) ozone $(25.8 \mathrm{ppb})$ in the hours prior to disease onset. Vertical bars indicate $95 \%$ confidence intervals. 
Table 4 Associations of an interquartile-range increase in SPM (24-48 hours), ozone (72-96 hours), and $\mathrm{SO}_{2}$ (0-24 hours) prior to emergency call with health outcomes in each subgroup of patients

\begin{tabular}{|c|c|c|c|c|c|c|}
\hline & \multicolumn{4}{|c|}{ Respiratory disease } & \multirow{2}{*}{\multicolumn{2}{|c|}{$\begin{array}{c}\text { Pneumonia and influenza } \\
\mathrm{SO}_{2}(0-24 \text { hours })\end{array}$}} \\
\hline & \multicolumn{2}{|c|}{ SPM (24-48 hours) } & \multicolumn{2}{|c|}{ Ozone (72-96 hours) } & & \\
\hline & OR $(95 \% \mathrm{Cl})^{\mathrm{a}}$ & $p^{\mathbf{b}}$ & OR $(95 \% \mathrm{Cl})^{a}$ & $p^{\mathbf{b}}$ & OR $(95 \% \mathrm{Cl})^{\mathrm{a}}$ & $p^{\mathrm{b}}$ \\
\hline \multicolumn{7}{|l|}{ Age (year) } \\
\hline$\geq 75$ & $1.06(1.02,1.10)$ & 0.33 & $1.13(1.03,1.24)$ & 0.93 & $1.08(1.01,1.16)$ & 0.25 \\
\hline$<75$ & $1.01(0.93,1.10)$ & & $1.14(0.94,1.38)$ & & $0.99(0.85,1.14)$ & \\
\hline \multicolumn{7}{|l|}{ Sex } \\
\hline Men & $1.07(1.02,1.12)$ & 0.25 & $1.07(0.95,1.19)$ & 0.12 & $1.04(0.95,1.13)$ & 0.30 \\
\hline Women & $1.02(0.97,1.08)$ & & $1.22(1.07,1.39)$ & & $1.10(1.01,1.21)$ & \\
\hline \multicolumn{7}{|l|}{ Onset } \\
\hline 8 am to $7 \mathrm{pm}$ & $1.05(1.00,1.09)$ & 0.69 & $1.12(1.01,1.24)$ & 0.79 & $1.07(0.99,1.15)$ & 1.00 \\
\hline $8 \mathrm{pm}$ to $7 \mathrm{am}$ & $1.06(0.99,1.14)$ & & $1.15(0.98,1.35)$ & & $1.07(0.94,1.21)$ & \\
\hline \multicolumn{7}{|l|}{ Past history } \\
\hline \multicolumn{7}{|l|}{ Hypertension } \\
\hline Yes & $1.08(0.95,1.23)$ & 0.63 & $1.28(0.95,1.74)$ & 0.37 & $1.25(1.00,1.56)$ & 0.13 \\
\hline No & $1.05(1.01,1.09)$ & & $1.11(1.01,1.22)$ & & $1.05(0.98,1.12)$ & \\
\hline \multicolumn{7}{|c|}{ Coronary heart disease } \\
\hline Yes & $1.17(0.94,1.46)$ & 0.35 & $1.37(0.85,2.23)$ & 0.41 & $1.09(0.77,1.53)$ & 0.90 \\
\hline No & $1.05(1.01,1.09)$ & & $1.12(1.02,1.22)$ & & $1.06(1.00,1.14)$ & \\
\hline \multicolumn{7}{|c|}{ Cerebrovascular disease } \\
\hline Yes & $1.03(0.93,1.14)$ & 0.61 & $1.01(0.81,1.25)$ & 0.28 & $0.94(0.81,1.09)$ & 0.08 \\
\hline No & $1.06(1.01,1.10)$ & & $1.15(1.04,1.26)$ & & $1.09(1.02,1.17)$ & \\
\hline \multicolumn{7}{|c|}{ Diabetes mellitus } \\
\hline Yes & $0.99(0.84,1.18)$ & 0.50 & $0.85(0.58,1.24)$ & 0.14 & $0.98(0.78,1.23)$ & 0.46 \\
\hline No & $1.05(1.02,1.10)$ & & $1.14(1.04,1.25)$ & & $1.07(1.00,1.14)$ & \\
\hline \multicolumn{7}{|c|}{ Respiratory disease } \\
\hline Yes & $1.01(0.94,1.09)$ & 0.24 & $1.15(0.96,1.37)$ & 0.80 & $0.92(0.79,1.08)$ & 0.04 \\
\hline No & $1.07(1.02,1.11)$ & & $1.12(1.01,1.23)$ & & $1.09(1.02,1.17)$ & \\
\hline
\end{tabular}

${ }^{a}$ Adjusted for ambient temperature $(\mathrm{df}=6)$, relative humidity $(\mathrm{df}=3)$, and weekly numbers of reported influenza cases aged $\geq 60$. Interquartile ranges are $20.6 \mu \mathrm{g} / \mathrm{m}^{3}$ for $\mathrm{SPM}, 2.3 \mathrm{ppb}$ for $\mathrm{SO}_{2}$, and $25.8 \mathrm{ppb}$ for ozone.

b $p$ value for interaction.

$\mathrm{Cl}$, Confidence interval; $\mathrm{SO}_{2}$, Sulfate dioxide; $S P M$, Suspended particulate matter.

significant. Because of the large number of tests we conducted, there is a possibility of chance findings.

Second, because we did not have the exact times of disease onsets, we used the time of emergency call as the disease onset for each case. Compared with cardiovascular disease, the disease onset of respiratory disease would be difficult to identify and the disease progression is probably gradual. Thus, the disease onset may only indicate the appearance of respiratory symptoms rather than incidence of disease. The present finding that shorter lag for $\mathrm{SO}_{2}$ than for SPM or ozone may just show the differences in latent periods [38] between disease onset and the need for emergency call, i.e., the different speed in disease progression of the disease which these air pollutants may induce.
Third, disease diagnosis was made by physicians at emergency rooms of the hospitals to which the patients were transported. In general, emergency patients are brought to large hospitals in the city of Okayama, where diagnostic technique is standardized. Although we used a definition of pneumonia and influenza together, 97\% of the patients $(n=3,116)$ were diagnosed pneumonia or lower respiratory infection (LRI); thus, the effect estimates obtained for pneumonia and influenza would be attributable to LRI. Indeed, when we excluded influenza cases from the analysis, the result did not change substantially.

A further limitation is that we assumed all residents were exposed to the same concentration without considering spatial distribution. However, the analyses restricted to 
20-km buffers from each monitoring station provided similar effect estimates.

Finally, we did not include patients who arrived at hospitals by their own means. Therefore, we might not be able to generalize the present findings to all emergency hospital visits.

\section{Conclusions}

The present study provides further evidence that hourly changes in air pollution exposure increase the risks of respiratory disease. Elevated risk for $\mathrm{SO}_{2}$ was observed at shorter lags (i.e., $8-18$ hours) than the elevated risks for SPM or ozone (i.e., lags of 1-4 days); thus, $\mathrm{SO}_{2}$ may be related with more immediate onset of the disease than SPM or ozone. These findings, derived from finer temporal resolution of air pollution, should provide additional insights into the physiological mechanisms of air pollution health effects as well as air pollution regulations.

\section{Abbreviations}

Cl: Confidence interval; CO: Carbon monoxide; COPD: Chronic obstructive pulmonary disease; df: Degree of freedom; ICD: International Classification of Disease; IQR: Interquartile range; LRI: Lower respiratory infection;

$\mathrm{NO}_{2}$ : Nitrogen dioxide; OR: Odds ratio; PM: Particulate matter; SD: Standard deviation; $\mathrm{SO}_{2}$ : Sulfate dioxide; SPM: Suspended particulate matter.

\section{Competing interests}

The authors declare that they have no competing interest.

\section{Authors' contributions}

Study concept and design: TY, ES, SK; Data collection: ES; Data handling: TY, SK; Analysis: TY; Interpretation of data: TY, ES, SK; Drafting of the manuscript TY; Critical revision of the manuscript: ES, SK. All authors read and approved the final manuscript

\section{Acknowledgments}

We thank Toshihide Tsuda for helping us to obtain the data and Saori Irie and Tsuguhiko Kato for helping us prepare the manuscript. The present study was supported by The Yakumo Foundation for Environmental Science and Grant-in-Aid for Scientific Research (C) No. 24510033 and No. 22390124 from the Japanese Ministry of Education, Culture, Sports, Science and Technology (MEXT).

\section{Author details}

'Department of Human Ecology, Graduate School of Environmental and Life Science, Okayama University, 3-1-1 Tsushima-naka, Kita-ku, Okayama 700-8530, Japan. ${ }^{2}$ Department of Epidemiology, Graduate School of Medicine, Dentistry and Pharmaceutical Sciences, Okayama University, 2-5-1 Shikata-cho, Kita-ku, Okayama 700-8558, Japan. ${ }^{3}$ Department of Public Health and Health Policy, Institute of Biomedical \& Health Sciences, Hiroshima University, 1-2-3 Kasumi, Minami-ku, Hiroshima 734-8551, Japan.

Received: 15 April 2014 Accepted: 8 August 2014

Published: 13 August 2014

\section{References}

1. Atkinson RW, Kang S, Anderson HR, Mills IC, Walton HA: Epidemiological time series studies of PM2.5 and daily mortality and hospital admissions: a systematic review and meta-analysis. Thorax 2014, 69:660-665.

2. Bentayeb M, Simoni M, Baiz N, Norback D, Baldacci S, Maio S, Viegi G, Annesi-Maesano I: Adverse respiratory effects of outdoor air pollution in the elderly. Int I Tuberc Lung Dis 2012, 16:1149-1161.

3. Guarnieri M, Balmes JR: Outdoor air pollution and asthma. Lancet 2014, 383:1581-1592.

4. Pope CA 3rd, Dockery DW: Health effects of fine particulate air pollution: lines that connect. J Air Waste Manag Assoc 2006, 56:709-742.
5. World Health Organization: Air quality guidelines: global update 2005: particulate matter, ozone, nitrogen dioxide, and sulfur dioxide. Copenhagen, Denmark: World Health Organization; 2006.

6. Katsouyanni K, Samet JM, Anderson HR, Atkinson R, Le Tertre A, Medina S, Samoli E, Touloumi G, Burnett RT, Krewski D, Ramsay T, Dominici F, Peng RD, Schwartz J, Zanobetti A: Air pollution and health: a European and North American approach (APHENA). Res Rep Health Eff Inst 2009, 5-90. http://www.ncbi.nlm.nih.gov/pubmed/20073322.

7. Darrow LA, Klein M, Sarnat JA, Mulholland JA, Strickland MJ, Sarnat SE, Russell AG, Tolbert PE: The use of alternative pollutant metrics in timeseries studies of ambient air pollution and respiratory emergency department visits. J Expo Sci Environ Epidemiol 2011, 21:10-19.

8. Stieb DM, Szyszkowicz M, Rowe BH, Leech JA: Air pollution and emergency department visits for cardiac and respiratory conditions: a multi-city time-series analysis. Environ Health 2009, 8:25.

9. Kim SY, Peel JL, Hannigan MP, Dutton SJ, Sheppard L, Clark ML, Vedal S: The temporal lag structure of short-term associations of fine particulate matter chemical constituents and cardiovascular and respiratory hospitalizations. Environ Health Perspect 2012, 120:1094-1099.

10. Bhaskaran K, Hajat S, Armstrong B, Haines A, Herrett E, Wilkinson P, Smeeth $L$ : The effects of hourly differences in air pollution on the risk of myocardial infarction: case crossover analysis of the MINAP database. BMJ 2011, 343:d5531.

11. Peters A, Dockery DW, Muller JE, Mittleman MA: Increased particulate air pollution and the triggering of myocardial infarction. Circulation 2001, 103:2810-2815.

12. Chen L, Villeneuve PJ, Rowe BH, Liu L, Stieb DM: The air quality health index as a predictor of emergency department visits for ischemic stroke in Edmonton, Canada. J Expo Sci Environ Epidemiol 2014, 24:358-364.

13. O'Donnell MJ, Fang J, Mittleman MA, Kapral MK, Wellenius GA: Fine particulate air pollution (PM2.5) and the risk of acute ischemic stroke. Epidemiology 2011, 22:422-431.

14. Wellenius GA, Burger MR, Coull BA, Schwartz J, Suh HH, Koutrakis P, Schlaug G, Gold DR, Mittleman MA: Ambient air pollution and the risk of acute ischemic stroke. Arch Intern Med 2012, 172:229-234.

15. Yamazaki S, Nitta H, Ono M, Green J, Fukuhara S: Intracerebral haemorrhage associated with hourly concentration of ambient particulate matter: casecrossover analysis. Occup Environ Med 2007, 64:17-24.

16. Mills NL, Tornqvist H, Gonzalez MC, Vink E, Robinson SD, Soderberg S, Boon NA, Donaldson K, Sandstrom T, Blomberg A, Newby DE: Ischemic and thrombotic effects of dilute diesel-exhaust inhalation in men with coronary heart disease. N Engl J Med 2007, 357:1075-1082.

17. Mills NL, Tornqvist H, Robinson SD, Gonzalez M, Darnley K, MacNee W, Boon NA, Donaldson K, Blomberg A, Sandstrom T, Newby DE: Diesel exhaust inhalation causes vascular dysfunction and impaired endogenous fibrinolysis. Circulation 2005, 112:3930-3936.

18. Ghio AJ, Kim C, Devlin RB: Concentrated ambient air particles induce mild pulmonary inflammation in healthy human volunteers. Am J Respir Crit Care Med 2000, 162:981-988.

19. Kim CS, Alexis NE, Rappold AG, Kehrl H, Hazucha MJ, Lay JC, Schmitt MT, Case M, Devlin RB, Peden DB, Diaz-Sanchez D: Lung function and inflammatory responses in healthy young adults exposed to $0.06 \mathrm{ppm}$ ozone for 6.6 hours. Am J Respir Crit Care Med 2011, 183:1215-1221.

20. Yorifuji T, Suzuki E, Kashima S: Cardiovascular emergency hospital visits and hourly changes in air pollution. Stroke 2014, 45:1264-1268.

21. Influenza surveillance (in Japanese). http://www.city.okayama.jp/hofuku/ hoken/hoken_s00050.html.

22. Yorifuji T, Kawachi I, Kaneda M, Takao S, Kashima S, Doi H: Diesel vehicle emission and death rates in Tokyo, Japan: a natural experiment. Sci Total Environ 2011, 409:3620-3627.

23. Janes $H$, Sheppard L, Lumley $\mathrm{T}$ : Case-crossover analyses of air pollution exposure data: referent selection strategies and their implications for bias. Epidemiology 2005, 16:717-726.

24. Schwartz J: The distributed lag between air pollution and daily deaths. Epidemiology 2000, 11:320-326.

25. R Core Team: $R$ : A language and environment for statistical computing. Vienna, Austria: R Foundation for Statistical Computing; 2013. URL http://www.R-project.org/.

26. Ji M, Cohan DS, Bell ML: Meta-analysis of the association between shortterm exposure to ambient ozone and respiratory hospital admissions. Environ Res Lett ERL [Web site] 2011, 6:024006. 
27. Kan H, Wong CM, Vichit-Vadakan N, Qian Z, Teams PP: Short-term association between sulfur dioxide and daily mortality: the Public Health and Air Pollution in Asia (PAPA) study. Environ Res 2010, 110:258-264.

28. Stieb DM, Judek S, Burnett RT: Meta-analysis of time-series studies of air pollution and mortality: effects of gases and particles and the influence of cause of death, age, and season. J Air Waste Manag Assoc 2002 52:470-484.

29. Sunyer J, Atkinson R, Ballester F, Le Tertre A, Ayres JG, Forastiere F, Forsberg B, Vonk JM, Bisanti L, Anderson RH, Schwartz J, Katsouyanni K, study A: Respiratory effects of sulphur dioxide: a hierarchical multicity analysis in the APHEA 2 study. Occup Environ Med 2003, 60:e2.

30. Hedley AJ, Wong CM, Thach TQ, Ma S, Lam TH, Anderson HR: Cardiorespiratory and all-cause mortality after restrictions on sulphur content of fuel in Hong Kong: an intervention study. Lancet 2002, 360:1646-1652.

31. Wong CM, Lam TH, Peters J, Hedley AJ, Ong SG, Tam AY, Liu J, Spiegelhalter DJ: Comparison between two districts of the effects of an air pollution intervention on bronchial responsiveness in primary school children in Hong Kong. J Epidemiol Community Health 1998, 52:571-578.

32. Omori T, Fujimoto G, Yoshimura I, Nitta H, Ono M: Effects of particulate matter on daily mortality in 13 Japanese cities. J Epidemiol 2003, 13:314-322.

33. Ghio AJ, Huang YC: Exposure to concentrated ambient particles (CAPs): a review. Inhal Toxicol 2004, 16:53-59.

34. Bell ML, Samet JM: Air pollution. In Environmental health: from global to local. 2nd edition. Edited by Frumkin H. San Francisco, CA: Jossey-Bass; 2010:387-415

35. Kan H, London SJ, Chen G, Zhang Y, Song G, Zhao N, Jiang L, Chen B: Season, sex, age, and education as modifiers of the effects of outdoo air pollution on daily mortality in Shanghai, China: the Public Health and Air Pollution in Asia (PAPA) study. Environ Health Perspect 2008, 116:1183-1188.

36. Ren C, Melly S, Schwartz J: Modifiers of short-term effects of ozone on mortality in eastern Massachusetts-a case-crossover analysis at individual level. Environ Health 2010, 9:3.

37. Faustini A, Stafoggia M, Cappai G, Forastiere F: Short-term effects of air pollution in a cohort of patients with chronic obstructive pulmonary disease. Epidemiology 2012, 23:861-879.

38. Rothman KJ: Epidemiology: an introduction. 2nd edition. New York, NY: Oxford University Press; 2012. risk of respiratory disease in the elderly: a time-stratified case-crossover study. Environmental Health 2014 13:67.

\section{Submit your next manuscript to BioMed Central and take full advantage of:}

- Convenient online submission

- Thorough peer review

- No space constraints or color figure charges

- Immediate publication on acceptance

- Inclusion in PubMed, CAS, Scopus and Google Scholar

- Research which is freely available for redistribution
C Biomed Central 